\title{
Erratum
}

\section{Vimentin mRNA Expression Increases After Corticospinal Axotomy in the Adult Hamster}

Susanne A. Mikucki and Monica M. Oblinger

(Originally published in Metabolic Brain Disease, Vol. 6, no. 1, 1991 pp. 33-49)

On page 44 of the above, the wrong legend appeared for Figure 5. The correct legend is as follows:

Fig. 5. Film autoradiograms of histological sections of brain stem after in situ hybridization with either vimentin (A, C, E) or GFAP (B,D,F) ${ }^{35}$ S-labeled cDNA probes. Examples from three different animals at 2 days (A-B) and 14 days $(\mathrm{C}-\mathrm{F})$ after unilateral transection of the corticospinal tract are shown. In all cases, the lesion side is on the right. Small black arrows (A) outline the uninjured corticospinal tract. Sections that were used for vimentin and GFAP hybridizations were from comparable levels of the brain stem. The sections in A-B are about $1 \mathrm{~mm}$ caudal to the lesion site. In C-D, the sections are at the level of the lesion (indicated by the asterisk). Sections in E-F are about $4 \mathrm{~mm}$ caudal to the lesion. At that level, the tract has crossed and assumed a position in the dorsal part of the spinal cord (arrowhead). The GFAP cDNA probe is described in Kost-Mikucki and Oblinger, 1991. 